\title{
Enucleation Followed by Open Packing of Iodoform Gauze in Mandibular Unicystic Ameloblastoma: A Case Report
}

\author{
Vijay Kumar' ${ }^{1}$, Raman Kant Sinha ${ }^{2}$ \\ ${ }^{1}$ Consultant Oral and Maxillofacial Surgeon, R. D. Dental Hospital \& Research Centre, Patna, India \\ ${ }^{2}$ Department of Oral \& Maxillofacial Pathology, Sarjug Dental College and Hospital, Darbhanga, India \\ Email: vijaypraveenmds@gmail.com
}

Received 7 May 2014; revised 17 June 2014; accepted 27 July 2014

Copyright (C) 2014 by authors and OALib.

This work is licensed under the Creative Commons Attribution International License (CC BY).

http://creativecommons.org/licenses/by/4.0/

(c) $\underset{\mathrm{EY}}{\mathrm{O}}$ Open Access

\begin{abstract}
Unicystic ameloblastoma is a clinical subtype of ameloblastoma. According to Ackermann there are three types of unicystic ameloblastoma microscopically. Luminal unicystic ameloblastoma belongs to the Ackermann type-1 unicystic ameloblastoma. They frequently affect young people and may behave aggressively. A general agreement has been made for aggressive type of unicystic ameloblastomas are managed aggressively to eradicate the lesions completely by radical surgical procedures that cause mutilation. Mutilation adversely affects the physcosocial condition of the patient particularly in young age. Therefore there is need of those procedures which restore patient's natural forms and functions till last attempt. The aim of this case report was to evaluate the efficacy of conservative surgical procedure (enucleation followed by iodoform gauze dressing) in aggressive type of unicystic ameloblastoma. During one year follow-up we observed uneventful secondary healing and bone regeneration, no sign of recurrence clinically and radiographically and no mutilation postoperatively.
\end{abstract}

\section{Keywords}

Unicystic Ameloblastoma, Conservative Treatment, Enucleation, Iodoform

Subject Areas: Dentistry, Pathology

\section{Introduction}

Ameloblastomas are benign odontogenic tumors having potential to grow into enormous size with resulting bone deformity [1]. Clinically ameloblastoma was classified into four sub-groups like solid or multicystic, unicystic, desmoplastic and extra-osseous or peripheral [2]. Unicystic ameloblastoma was commonly reported in 
young patients and it was first described by Robinson and Martinez in 1977 [2] [3]. Ackermann classified this entity into three groups 1) luminal, 2) intra-luminal and 3) mural pattern) while Philipsen and Reichart classified unicystic ameloblastoma into four sub-groups: A) luminal, B) luminal and intra-luminal, C) luminal, intra-luminal and intramural and D) luminal and intramural on the basis of histopathology. Unicystic ameloblastoma diagnosed as sub-group A and B can be treated conservatively like careful enucleation with/without adjunctive therapy, whereas sub group C and D required radical resection, as for a solid or multicystic ameloblastoma [4] [5]. According to recent literatures, if cortical perforation was present then it behaves like solid ameloblastoma and managed accordingly [1]. Aggressive surgical approach like resection with or without continuity defects may cause mutilation. Mutilation adversely affects the physcosocial condition of the patient particularly in young patient. Therefore, our primary aim is to restore its natural forms and functions till last attempt to avoid mutilation [6]-[9].

This case report was performed to evaluate the success of conservative treatment like surgical enucleation followed by iodoform gauze dressing in luminal unicystic ameloblastoma of the mandible.

\section{Case Report}

A 21-year-old male patient reported to our centre with complaint of swelling and occasional pain in relation to lower left posterior teeth region since last 5 months. Patient was asymptomatic 5 months back then he noticed, insidious in onset and gradually progressive. There was no history of dental infection/trauma. The medical history of patient was unremarkable. On extraoral examination, facial asymmetry was apparent with a diffused swelling involving the left side of mandible, measuring $4.5 \mathrm{~cm} \times 4 \mathrm{~cm}$ (Figure 1(A)). The swelling was soft and tender on palpation. While intraoral examination revealed multiple retained $(53,71,75,85)$ and missing teeth $(13,18,31,35,38,41,45,48)$ as well as both cortical plate expansion in relation to 75,36 and 37 with vestibular obliteration (Figure 1(B)).

On radiographic examination, OPG revealed unilocular well capsulated radiolucent lesion that extend from distal surface of left mandibular first premolar to apices of second molar and less than $1 \mathrm{~cm}$ of residual lower border as well as alveolar process on the same along with inferior alveolar nerve involvement (Figure 3(A)). Axial CT revealed fairly large $(3.5 \mathrm{~cm} \times 3.2 \mathrm{~cm} \times 3 \mathrm{~cm})$ well defined rounded cystic destructive lesion involving left mandibular body with large exophytic component (Figure 2(A)) while 3D CT of mandible revealed complete loss of osseous component in the same (Figure 2(B)).

Fine needle aspiration yielded $10 \mathrm{ml}$ of blood mixed fluid and tissue was obtained from the lesion was submitted for the histopathological examination (Figure 2(C)). Microscopic examination reveals presence of fibrous wall which is lined by ameloblastic epithelium. These ameloblastic epithelium exhibits columnar differentiation and reverse polarization of basal cell layer. The basal cell layer is hyperchromatic and contracts with the reminder which is loose and eosinophilic. The fibrous wall is loose and reveals the presence of scattered fibroblast and chronic inflammatory cells chiefly lymphocytes and extravasated RBCs. Therefore overall histopathological features are suggestive of Luminal Unicystic Ameloblastoma (Figure 2(D) \& Figure 2(E)).

Due to large size of lesion, involvement of IAN and loss of buccal as well as lingual cortex, our treatment plan was enucleation followed by open packing and subsequently the involved teeth were removed under GA. With the help of lower vestibular incision, surgical site was exposed; the lesion looks like capsulated brownish blue in appearance as well as complete loss of osseous component antero-posteriorly and less than $1 \mathrm{~cm}$ residual bone in relation to alveolous and lower border. Thus our main intention was to preserve the periosteum and residual bone as much as possible to achieve uneventful hard tissue healing during follow-up. The resulting cavity was properly irrigated and finally packed with iodoform gauze. The wound was evaluated at interval of every 7 days and packed was changed till complete soft tissue healing [9] [10]. In this case complete soft (Figure 1(C)) and hard tissue healing was achieved at about $4^{\text {th }}$ months and 1 year postoperatively respectively. On follow-up, we noticed slight bleeding during $\left(1^{\text {st }}, 2^{\text {nd }}, 3^{\text {rd }}\right.$ and $\left.4^{\text {th }}\right)$ dressing that resolved after iodoform pack given and panoramic radiograph was taken after $6^{\text {th }}$ weeks (Figure 3(B)), $4^{\text {th }}$ months (Figure $3(C)$ ) and 1 year (Figure 3(D)). During one year follow-up we observed uneventful secondary healing and bone regeneration, no sign of recurrence clinically and radiographically and no mutilation postoperatively (Figure 1(D)).

\section{Discussion}

Ameloblastomas are the most common, clinically significant and potentially lethal benign odontogenic tumor [11]. 

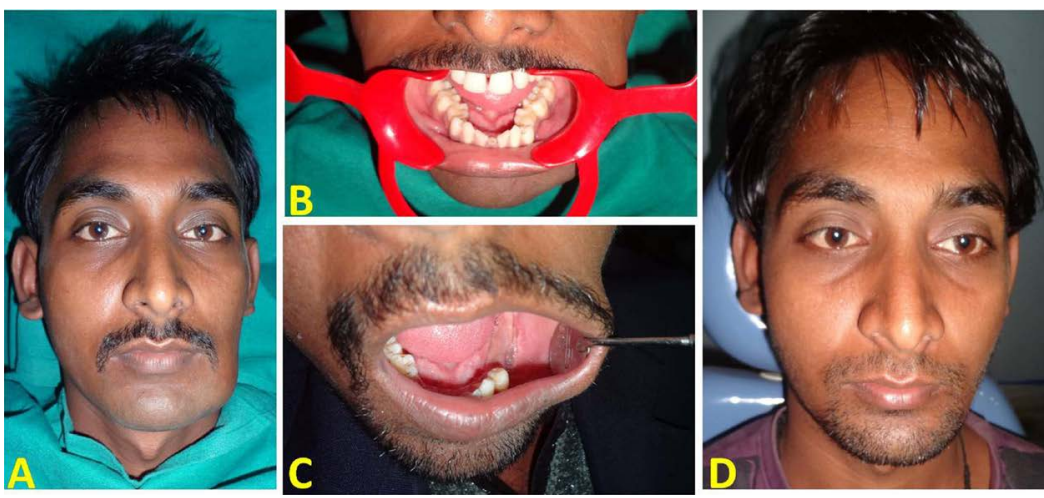

Figure 1. (A) Extraoral Preoperative photograph, (B) Intraoral Preoperative photograph, (C) Intraoral Postoperative photograph and (D) Extraoral Postoperative photograph.
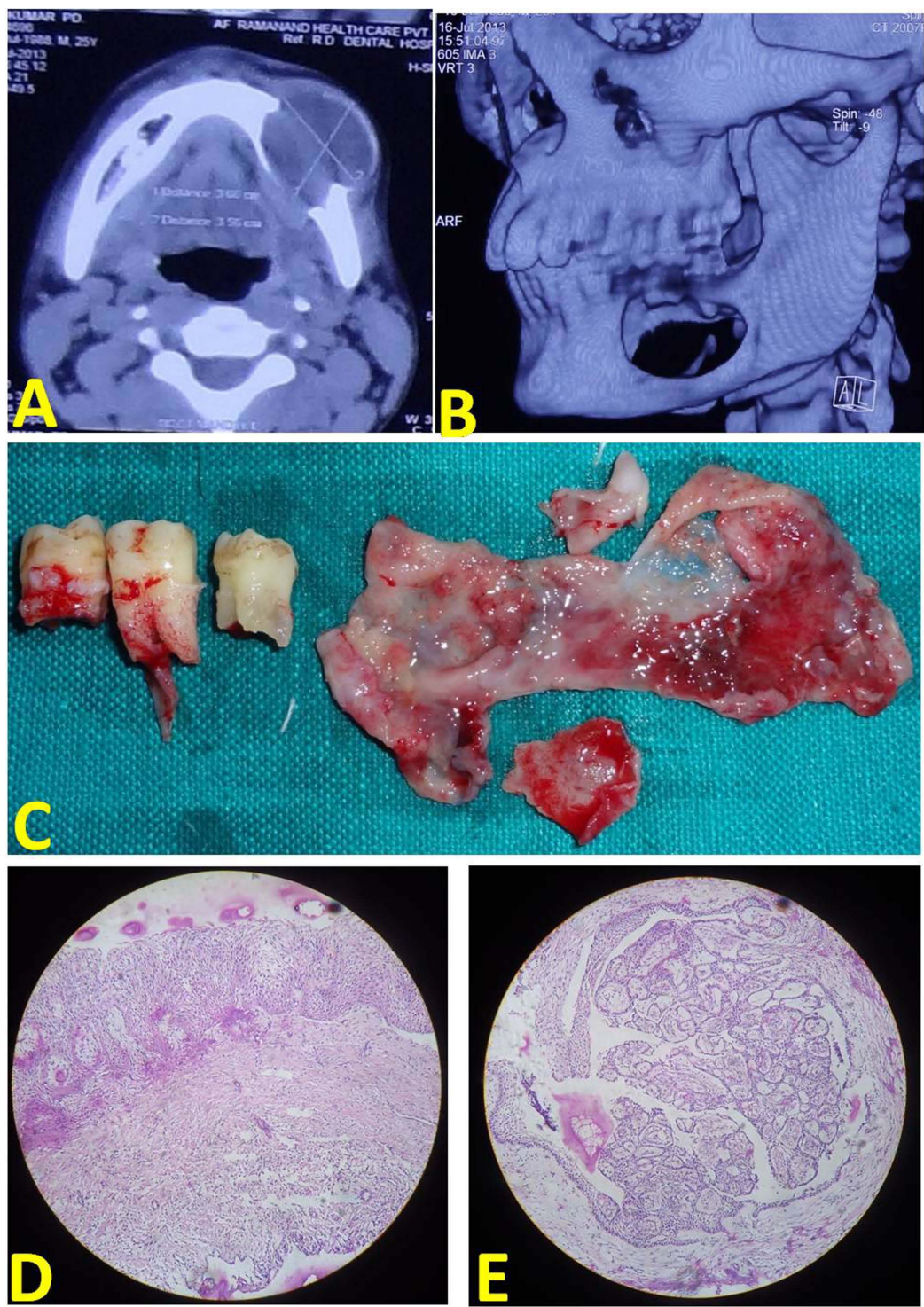

Figure 2. (A) Axial CT, (B) 3D CT, (C) Gross Specimen and (D \& E) 10× microscopic photographs. 


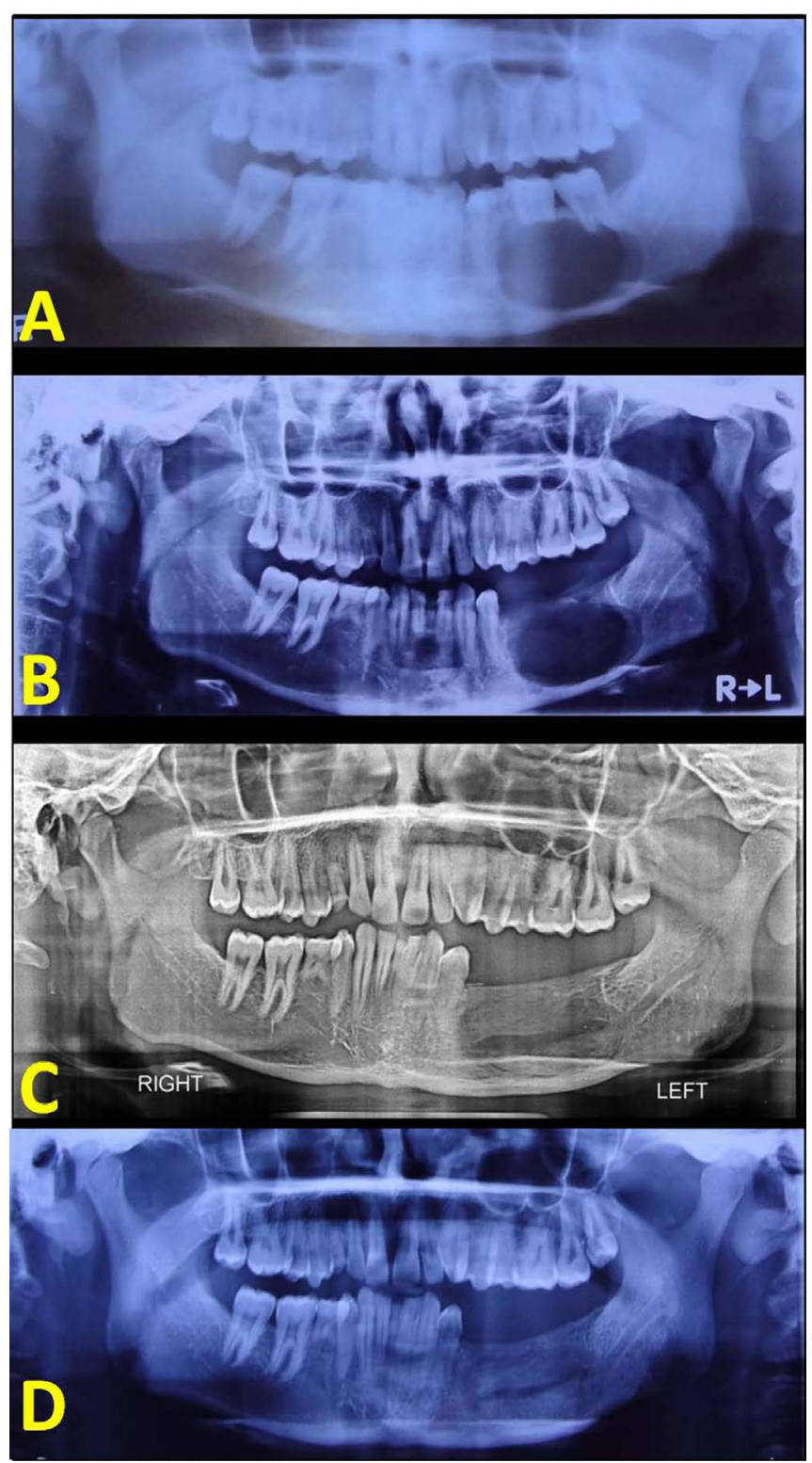

Figure 3. (A) Preoperative OPG, (B) $6^{\text {th }}$ weeks Postoperative OPG, (C) 4 months Postoperative OPG, and (D) one year Postoperative OPG.

It may cast a unilocular cystic radiolucency or a multilocular image like soap bubble or the honeycomb appearance. In early stages it grows slowly and silently without clinical signs. Later, it causes migration, tipping and mobility of teeth; root resorption and paresthesia of the lip. In advanced stages, it may frequently expand and erodes the cortical plates and invade the soft tissue. At this point the ameloblastoma severely interfere the forms and functions of the patients on other hand uncontrolled ameloblastoma may causes significant morbidity and occasional death [12] [13]. They occur mainly in the mandible with incidence of posterior mandible $>$ parasymphysis region > anterior maxilla > posterior maxilla [14]. According to Kim et al. diagnosis of ameloblastoma in young people remains in doubt after clinical and radiological examination because some overlaping features that's why biopsy is necessary [5] [15]. Differential diagnosis of unicystic ameloblastoma includes dentigerous cysts, odontogenic keratocyst, residual cysts, adenomatoid odontogenic tumor (AOT), gaint cell lesions and sometimes solid ameloblastoma. However, keratocyst seldom shows cortical expansion, residual cysts are associated with missing teeth, AOT has a predilection for anterior maxilla, central gaint cell granuloma often arises 
anterior to the first mandibular molar and solid ameloblastoma uncommonly in pateints less than 30 years of age [14].

As per English literatures, there is still controversy about the treatment based on the clinical and/or radiological presentation or histopathological characteristics of the tumors. Reported treatment options for ameloblastomas are resection (marginal or segmental) with/without reconstruction, enucleation, curettage, marsupalization or combination of these techniques with/without some adjunctive procedures (Carnoy's solution, Cryotherapy etc). The recurrence rates of ameloblastomas are reported to be as high as $15 \%$ to $25 \%$ after radical treatment and $55 \%$ to $90 \%$ after conservative treatment. On the other hand, recent advances in the understanding of the biological features of ameloblastomas have lead to more successful conservative surgical treatments [16] [17]. Unicystic ameloblastoma diagnosed as microscopic sub-group A and B can be treated conservatively like careful enucleation with/without adjunctive therapy but if cortical perforation was present than it behaves like solid ameloblastoma and managed accordingly [1] [4]. A general agreement was made to eradicate these lesions completely with the help of aggressive surgical approach like resection with or without continuity defects. These surgical procedures may cause severe deformity postoperatively that adversely affects the physcosocial condition of the patient particularly in young age [6]-[9].

Previous literatures also reported that, large surgical cavity created by enucleation is better to allowed secondary wound healing rather than primary closer because it may causes postoperative infection due to presence of large dead space [3] [6] [7]. Dressing material used to allow secondary wound healing in mouth has following properties (reduces postoperative pain, promote healing and prevent infection). Iodoform is one of them because they reduces wound fluids by fibrinolytic activity, exhibits antimicrobial activity after topical application and covers denuded bone surface to reduce pain [10] [18] [19]. Recent literatures also reported that decompression or marsupialization alters the epithelial lining of KCOT into less aggressive form and some tumors were completely resolved clinically and radiographically [6] [7]. On the basis of above findings, we preferred enucleation followed by iodoform gauze dressing for this case to restore its natural forms and functions because patient was very young.

Zhou $\mathrm{H}$ et al. in 2012 reported that, first two dressing required local anesthesia and minor bleeding was observed during fist two months dressing that resolved after repacking. According to him, average duration of packing was 10.2 months (range 7 - 15 months) by clinical assistants [7]. In our case, no need of local anesthesia in any dressing, slight bleeding was observed in first 4 dressing that also resolved by repacking and duration of packing was 4 months. These differences might be due to difference in case handling by clinical assistant and skilled doctor. Other possible regions were difference of the age of the patients and size of the lesions. Hadziabdic $\mathrm{N}$ et al. and Yildirim $\mathrm{G}$ et al. reported that radiographically complete bone healing was achieved in about 12 months and 16 months respectively [6] [20]. Similar result was found in our case. According to Bhutia $\mathrm{O}$ et al., if closely related teeth with the tumor are extracted can reduced the rate of recurrence. In our case all associated teeth were also removed [21]. During follow-up we observed uneventful secondary healing and bone regeneration, no sign of recurrence clinically and radiographically and no mutilation postoperatively.

\section{Conclusion}

If cortical perforation was encountered in unicystic ameloblastoma a general agreement was made to consider as a solid or multicystic ameloblastoma and managed accordingly. Management of solid or multicystic ameloblastoma is to eradicate the lesions completely by radical surgical procedures. On the other hand, most of unicystic ameloblastoma was commonly encountered in very young age and such type of surgical procedures causes mutilation that was not accepted. That's why we preferred a conservative surgical procedure like enucleation followed by iodoform gauze dressing to avoid mutilation. During one year follow-up we recorded no recurrence and uneventful secondary healing. We also recommended long clinical and radiographical follow-up due to its aggressive behavior.

\section{References}

[1] Gupta, N., Saxena, S., Rathod, V.C. and Aggarwal, P. (2011) Unicystic Ameloblastoma of the Mandible. Journal of Oral Maxillofacial Pathology, 15, 228-231. http://dx.doi.org/10.4103/0973-029X.84511

[2] Menditti, D., Laino, L., Marco, G.D., Rosa, A.D., Mellone, P. and Baldi, A. (2011) Unicystic Ameloblastoma of the Mandible. In Vivo, 25, 125-128. 
[3] Kalaskar, R., Unawane, A.S., Kalaskar, A.R. and Pandilwar, P. (2011) Conservative Management of Unicystic Ameloblastoma in a Young Child: Report of Two Cases. Contemporary Clinical Dentistry, 2, 359-363. http://dx.doi.org/10.4103/0976-237X.91804

[4] Ramesh, R.S., Manjunath, S., Ustad, T.H., Pais, S. and Shivakumar, K. (2010) Unicystic Ameloblastoma of the Mandible-An Unusual Case Report and Review of Literature. Head \& Neck Oncology, 2, 1. http://www.headandneckoncology.org/content/2/1/1 http://dx.doi.org/10.1186/1758-3284-2-1

[5] Dolanmaz, D., Etoz, O.A., Pampu, A., Kalayci, A. and Gunhan, O. (2011) Marsupialization of Unicystic Ameloblastoma: A Conservative Approach for Aggressive Odontogenic Tumors. Indian Journal of Dental Research, 22, 709-712. http://dx.doi.org/10.4103/0970-9290.93461

[6] Yildirim, G., Ataoglu, H., Kalayci, A., Ozkan, B.T., Kucuk, K. and Esen, A. (2010) Conservative Treatment Protocol for Keratocyst Odontogenic Tumour: A Follow-Up Study of 3 Cases. Journal of Oral \& Maxillofacial Research, 1 , e7. http://dx.doi.org/10.5037/jomr.2010.1307

[7] Zhou, H., Hou, R., Ma, Q., Wu, K., Ding, Y., Qui, R. and Hu, K. (2012) Secondary Healing after Removal of Large Keratocystic Odontogenic Tumor in the Mandible: Enucleation Followed by Open Packing of Iodoform Gauze. Journal of Oral and Maxillofacial Surgery, 70, 1523-1530. http://dx.doi.org/10.1016/j.joms.2011.12.021

[8] Scariot, R., Silva, R.V.D., Felix Jr., W.D.S., Costa, J.D. and Rebellato, N.L.B. (2012) Conservative Treatment of Ameloblastoma in Child: A Case Report. Stomatologija, Baltic Dental and Maxillofacial Journal, 14, 33-36.

[9] Giuliani, M., Grossi, G.B., Lajolo, C., Bisceglia, M. and Herb, K.E. (2006) Conservative Management of a Large Odontogenic Keratocyst: Report of a Case and Review of the Literature. Journal of Oral and Maxillofacial Surgery, 64, 308-316. http://dx.doi.org/10.1016/j.joms.2005.10.013

[10] Maria, A., Sharma, Y. and Chabbria, A. (2012) Marsupialization as a Treatment Option of a Large Odontogenic Keratocyst: A Case Report with the Review of Literature. People's Journal of Scientific Research, 5, 46-51.

[11] Miloro, M., Ghali, G.E., Larsen, P.E. and Waite, P.D. (2004) Peterson’s Principles of Oral and Maxillofacial Surgery. 2nd Edition, BC Decker Inc., Hamilton, London, Vol-1: 583.

[12] Wood, N.K. and Goaz, P.W. (1997) Differential Diagnosis of Oral and Maxillofacial Lesions. 5th Edition, Mosby (An Imprint of Elsevier), Maryland Heights, 337-338.

[13] Mendenhall, W.M., Werning, J.W., Fernandes, R., Malyapa, R.S. and Mendenhall, N.P. (2007) Ameloblastoma. American Journal of Clinical Oncology, 30, 645-648. http://dx.doi.org/10.1097/COC.0b013e3181573e59

[14] Yunus, M., Baig, N., Haque, A.V., Aslam, A., Atique, S., Bostan, S. and Sayed, A.M. (2009) Unicystic Ameloblastoma: A Distinct Clinicopathologic Entity. Pakistan Oral and Dental Journal, 29, 9-12.

[15] Kim, S.G. and Jang, H.S. (2001) Ameloblastoma: A Clinical, Radiographic and Hiistopathological Analysis of 71 Cases. Oral Surgery, Oral Medicine, Oral Pathology, Oral Radiology, Endodontology, 91, 649-653.

[16] Hasegawa, T., Imai, Y., Takeda, D., Yasuoka, D., Ri, S., Shigeta, T., Minamikawa, T., Shibuya, Y. and Komori, T. (2013) Retrospective Study of Ameloblastomas: The Possibility of Conservative Treatment. Kobe Journal of Medical Sciences, 59, E112-E121.

[17] Kahairi, A., Ahmad, R.L., Islah, L.W. and Norra, H. (2008) Management of Large Mandibular Ameloblastomas-A Case Report and Literature Reviews. Archives of Orofacial Sciences, 3, 52-55.

[18] Mizokami, F., Murasawa, Y., Furuta, K. and Isogai, Z. (2012) Iodoform Gauze Removes Necrotic Tissues from Pressure Ulcer Wounds by Fibrinolytic Activity. Biological and Pharmaceutical Bulletin, 35, 1048-1053. http://dx.doi.org/10.1248/bpb.b11-00016

[19] Freedman, M. and Stassen, L.F.A. (2013) Commonly Used Topical Oral Wound Dressing Materials in Dental and Surgical Practice-A Literature Review. Journal of the Irish Dental Association, 59, 190-195.

[20] Hadziabdic, N., Sulejmanagic, H., Selimovic, E. and Sulejmanagic, N. (2011) Therapeutic Approach to Large Jaw Cysts. HealthMED, 5, 1793-1799.

[21] Bhutia, O., Choudhury, A.R., Arora, A. and Mallick, S. (2013) Management of Unicystic Ameloblastoma of the Mandible in a 5-Year Old Child. National Journal of Maxillofacial Surgery, 4, 232-234. http://dx.doi.org/10.4103/0975-5950.127658 